\title{
"Stable-on-the-Table" Biosensors: Hemoglobin-Poly (Acrylic Acid) Nanogel BioElectrodes with High Thermal Stability and Enhanced Electroactivity
}

\section{Ananta Ghimire ${ }^{1}$, Omkar V. Zore ${ }^{1}$, Vindya K. Thilakarathne ${ }^{1}$, Victoria A. Briand ${ }^{1}$, Patrick J. Lenehan ${ }^{3}$, Yu Lei ${ }^{4}$, Rajeswari M. Kasi ${ }^{1,2, *}$ and Challa V. Kumar ${ }^{1,2,3, *}$}

1 Department of Chemistry, University of Connecticut, Storrs, CT 06269, USA;

E-Mails: ananta.ghimire@uconn.edu (A.G.); omkar.zore@uconn.edu (O.V.Z.); vindyakalani@gmail.com (V.K.T.); victoria.briand@gmail.com (V.A.B.)

2 Institute of Materials Science, U-3136, University of Connecticut, Storrs, CT 06269, USA

3 Department of Molecular and Cell Biology, University of Connecticut Storrs, Storrs, CT 06269, USA; E-Mail: patrick.lenehan@uconn.edu

4 Department of Chemical and Biomolecular Engineering, University of Connecticut, Storrs, CT 06269, USA; E-Mail: ylei@engr.uconn.edu

* Authors to whom correspondence should be addressed; E-Mails: kasi@uconn.edu (R.M.K.); challa.kumar@uconn.edu (C.V.K.); Tel.: +1-860-486-3213 (C.V.K.); Fax: +1-860-486-2981 (C.V.K.).

Academic Editor: Alexander Star

Received: 10 August 2015 / Accepted: 11 September 2015 / Published: 18 September 2015

\begin{abstract}
In our efforts toward producing environmentally responsible but highly stable bioelectrodes with high electroactivities, we report here a simple, inexpensive, autoclavable high sensitivity biosensor based on enzyme-polymer nanogels. Met-hemoglobin $(\mathrm{Hb})$ is stabilized by wrapping it in high molecular weight poly(acrylic acid) (PAA, $M_{\mathrm{w}} 450 \mathrm{k}$ ), and the resulting nanogels abbreviated as $\mathrm{Hb}-\mathrm{PAA}-450 \mathrm{k}$, withstood exposure to high temperatures for extended periods under steam sterilization conditions $\left(122{ }^{\circ} \mathrm{C}, 10 \mathrm{~min}, 17-20 \mathrm{psi}\right)$ without loss of $\mathrm{Hb}$ structure or its peroxidase-like activities. The bioelectrodes prepared by coating Hb-PAA-450k nanogels on glassy carbon showed well-defined quasi-reversible redox peaks at -0.279 and $-0.334 \mathrm{~V}$ in cyclic voltammetry $(\mathrm{CV})$ and retained $>95 \%$ electroactivity after storing for 14 days at room temperature. Similarly, the bioelectrode showed $\sim 90 \%$ retention in electrochemical properties after autoclaving under steam sterilization conditions. The ultra stable bioelectrode was used to detect hydrogen peroxide and demonstrated an excellent detection limit of $0.5 \mu \mathrm{M}$, the best among the $\mathrm{Hb}$-based
\end{abstract}


electrochemical biosensors. This is the first electrochemical demonstration of steam-sterilizable, storable, modular bioelectrode that undergoes reversible-thermal denaturation and retains electroactivity for protein based electrochemical applications.

Keywords: electrochemistry; biocatalysis; hemoglobin; high temperature catalysis; steam sterilization; polyacrylic acid

\section{Introduction}

Redox enzyme based electrodes have attracted increasing interest because of their applications in sensing, biofuel cells and bioelectronic devices [1]. Among many redox proteins, met-hemoglobin (Hb) is considered as a model to study direct electrochemistry-based biosensors, because of its catalytic activity and commercial availability. Although hemoglobin comprises of four iron containing heme groups, its electron transfer activity is hindered due to the extended three dimensional protein envelope around the heme, which buries the electroactive centers away from the electrode surfaces [2]. As a result, only a weak redox current appears with Hb-based electrodes on application of large over voltages. The electron transfer rate may be enhanced by the addition of promoters and mediators such as surfactants [3], polymers [4] and specific nanomaterials [5]. Using different techniques, Hb has been embedded in these films, which led to enhanced electron transfer rates, as well as better adhesion to the electrode surface. This facilitated the use of Hb-based electrodes for biosensing in food, pharmaceutical, clinical and environmental issues. Despite all this progress, a major concern and unmet challenge is the poor stability of $\mathrm{Hb}$ and $\mathrm{Hb}$ encapsulated derivatives under non-physiological environments, such as high temperatures, extreme pHs, and electrode surface [6].

Improved thermal stabilities of enzyme electrodes will directly enhance the shelf life for storage at ambient temperatures and facilitate biocatalysis and electrocatalysis at higher temperatures. Particularly, steam-sterilizable bioelectrodes will be useful for biomedical applications. Therefore, there is an urgent need to develop methods to stabilize $\mathrm{Hb}$, as an example, and characterize these new materials for use as bioelectrodes.

A variety of approaches were developed to enhance protein thermal stability, such as (i) intercalation in layered materials [7-14] and (ii) introducing multiple covalent attachment points to a polymer which may lead to restricted unfolding and conformational stabilization $[15,16]$. Protein properties are enhanced by forming hydrophilic matrix around the protein [17] via the construction of enzyme polymer conjugates [18-23].

We are interested in enhancing storage, shelf-life and thermal stabilities of enzymes and proteins by covalent conjugation with water soluble, flexible polymers, such as poly(acrylic acid) (PAA) [24]. The synthesis and characterization of Hb-PAA nanoparticles using low molecular weight PAA $(M \mathrm{w} 8 \mathrm{k})$ was reported earlier and these withstood steam sterilized conditions without significant loss of structure or biological activities. However, the particle nature of Hb-PAA-8k nanoparticle platform is not favorable for electrochemical application because $\mathrm{Hb}$ is encapsulated in the polymer nanoparticles, potentially hindering the accessibility of $\mathrm{Hb}$ active center to the electrode surface. Additionally, the nanoparticles limit the number of $\mathrm{Hb}$ molecules that could be brought close to the electrode surface and some $\mathrm{Hb}$ molecules 
may be far from the electrode surface. Conversely, protein-polymer nanogels could be more amenable to enhance electrical contact between the redox active sites and the electrode surfaces. However, when low molecular weight PAA was used to form $\mathrm{Hb}$-PAA nanogels, $\mathrm{Hb}$ was not protected against steam sterilization conditions $\left(122{ }^{\circ} \mathrm{C}, 17-20 \mathrm{psi}, 10 \mathrm{~min}\right)$ [24].

To amend the above-mentioned issues, we currently report the use of high molecular weight PAA ( $\mathrm{w}_{\mathrm{W}} 450 \mathrm{k}$ ) to cross-link $\mathrm{Hb}$ molecules and form unique $\mathrm{Hb}$-nanogels such that their thermal stability as well electroactivity at the electrode surface may be improved. This can be due to increased rigidity to the local environment surrounding $\mathrm{Hb}$ by the higher molecular weight polymer. The mole ratio of $\mathrm{Hb}: \mathrm{PAA}$ was optimized and its molecular weight increased such that low overlap concentrations of the high molecular weight PAA would favor nanogel formation instead of nanoparticles. In addition, the mole ratio of the crosslinking reagent (carbodiimide) to the number of $\mathrm{COOH}$ groups of PAA that are available for linking to the protein has been optimized systematically to produce water-soluble, highly active and thermally stable nanogels. Furthermore, PAA matrix around $\mathrm{Hb}$ was further strengthened by cross-linking carboxylic acid groups of PAA with tetraethylenepentamine (TEPA) or polyenthyleneimine (PEI) using the carbodiimide chemistry.

In this manuscript, by optimizing the $M_{\mathrm{w}}$ of PAA, reactant mole ratios and the crosslinking conditions, we obtained novel Hb-PAA nanogels that are stable at high temperatures and also show excellent electrochemical behavior over extended periods of time, which, to the best of our knowledge, has not been realized before. We also show that $\mathrm{Hb}$, by itself, has poor adhesion to the electrode surface and poor electron transfer rates (Scheme 1, top) while the nanogels are superior. Additionally, $\mathrm{Hb}$ in these nanogels undergoes reversible thermal denaturation, while Hb by itself does not (Scheme 1).

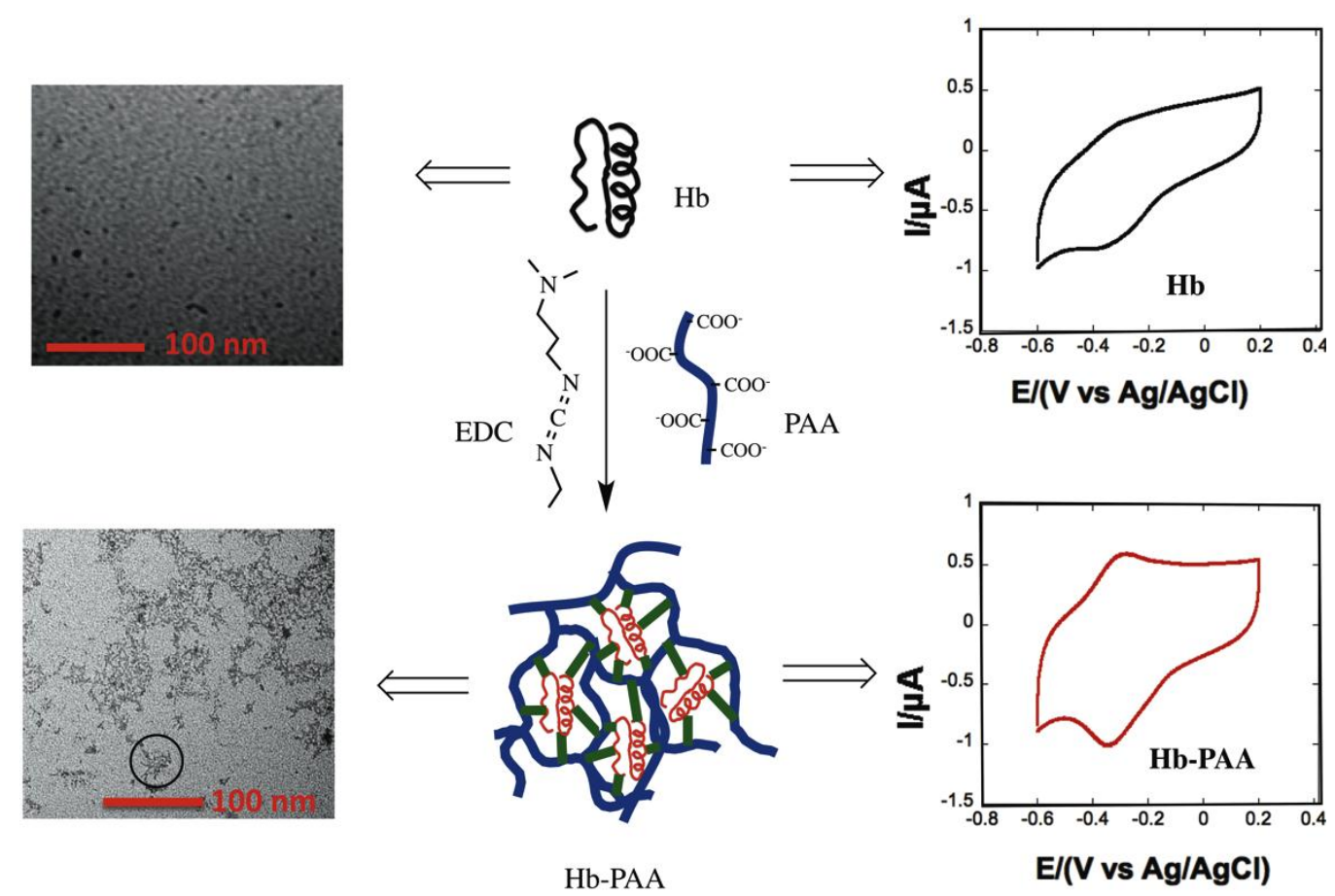

Scheme 1. Hemoglobin binding to PAA (Middle) and their corresponding cyclic voltammograms (Right) and TEM's (Left). TEM image of Hb-PAA shows the formation of nanogels (also shown in circle). 
More importantly, we exploit this general approach of random conjugation of $\mathrm{Hb}$ to PAA to build, for the first time, excellent bioelectrodes, which not only show better adhesion to the electrode surface and enhanced electron transfer rates but also better function at elevated temperatures and these are sterilizable in an ordinary autoclave without significant loss of electroactivity.

\section{Experimental Section}

Poly(acrylic acid ) ( $\left.M_{\mathrm{w}} 450 \mathrm{k}, M_{\mathrm{w}} 8 \mathrm{k}\right)$, polyethyleneimine (PEI, 8k), tetraethylene pentamine (TEPA), 1-ethyl-3(3-dimethylaminopropyl) carbodiimide (EDC), o-methoxyphenol, hydrogen peroxide $\left(\mathrm{H}_{2} \mathrm{O}_{2}\right)$ were purchased from Sigma-Aldrich (St. Louis, MO, USA). Bovine hemoglobin was obtained from MP Biomedicals (Solon, OH, USA).

\subsection{Synthesis of Hb-PAA Nanogel Conjugates}

PAA stock solution ( $2 \mathrm{wt} \%$ in water) of $\mathrm{pH} 7$ was prepared by dissolving appropriate amount of PAA in DI water and $\mathrm{pH}$ was adjusted by adding concentrated $\mathrm{NaOH}$. Hb stock solution $(26 \mathrm{mg} / \mathrm{mL})$ was prepared by slowly dissolving the enzyme in $10 \mathrm{mM}$ phosphate buffer at $\mathrm{pH} 7$. According to the amount of PAA and ratio of PAA:EDC (Supplementary Materials Table S1), EDC was mixed with PAA and stirred for $15 \mathrm{~min}$ to activate the PAA. $\mathrm{Hb}$ in phosphate buffer was then added to EDC activated PAA solution. The reaction was stirred gently for four $h$. The reaction mixture was dialyzed three times using $25 \mathrm{k}$ dialysis membranes against $10 \mathrm{mM}$ phosphate buffer $\mathrm{pH}$ 7. Dialyzed conjugates were used for further experiments. The samples were referred to as Hb-PAA-450k(1:0.8:1.5) and Hb-PAA-450k(1:0.3:1.5) based on the molar ratio of Hb:PAA:EDC. Therefore, Hb-PAA-450k(1:0.8:1.5) has Hb:PAA ratio as 1.3:1 and Hb-PAA-450k(1:0.3:1.5) has 3.4:1.

\subsection{PAA-Hb Nanogel Conjugates Cross-Linking with Polyamines}

PEI, $M_{\mathrm{w}} 8 \mathrm{k}$ and TEPA were used to cross link selected Hb-PAA conjugates, for example, Hb-PAA-450k(1:0.8:1.5). Stock solutions of polyamines were prepared in DI water and the pH was adjusted to 7 using concentrated $\mathrm{HCl}$. Only $0.2 \%$ of $\mathrm{COOH}$ groups were modified using TEPA (denoted as Hb-PAA-450k(1:0.8:1.5)-TEPA) and $0.7 \%$ of $\mathrm{COOH}$ were modified with PEI (denoted as Hb-PAA-450k(1:0.8:1.5)-PEI). Before adding polyamines to the Hb-PAA conjugate, EDC was added to the conjugate (EDC:COOH ratio is $2: 1$ ) and stirred $15 \mathrm{~min}$. After addition of TEPA the reaction mixture was stirred another $4 \mathrm{~h}$ and dialyzed using $25 \mathrm{k}$ dialysis membranes with $10 \mathrm{mM}$ phosphate buffer $\mathrm{pH} 7$ three times.

\subsection{Circular Dichroism Studies}

Secondary and tertiary structure retention of $\mathrm{Hb}$ after chemical modification in the presence and absence of PAA was determined using circular dichroism studies. Far UV and Soret CD spectra of Hb, and those in the presence of PAA were recorded using Jasco 710 spectropolarimeter. All samples were in PBS pH 6.4 buffer and the buffer spectrum was subtracted during processing. Step resolution was kept at $0.2 \mathrm{~nm} /$ data point and bandwidth and sensitivity were $1 \mathrm{~nm}$ and 20 millidegrees, respectively. When collecting far UV CD spectra each sample was scanned from $200 \mathrm{~nm}$ to $260 \mathrm{~nm}$ and scan speed 
was maintained at $50 \mathrm{~nm} / \mathrm{min}$. Average of four accumulations were recorded using $0.05 \mathrm{~cm}$ path length cuvettes. Same samples were used to collect Soret CD spectra and each sample was scanned from 350 to $450 \mathrm{~nm}$ and the scan speed was $50 \mathrm{~nm} / \mathrm{min}$. Path length used was $1.0 \mathrm{~cm}$ and eight accumulations were averaged to get each spectrum.

\subsection{Catalytic Activity Studies}

The catalytic activities of the Hb-PAA nanogel conjugates were evaluated in term of the peroxidase activity of $\mathrm{Hb}$ by following reported methods [24] The substrate, O-methoxyphenol (2.5 $\mathrm{mM})$ and the oxidant, $\mathrm{H}_{2} \mathrm{O}_{2}(1 \mathrm{mM})$ were added to the solution containing $1 \mu \mathrm{M} \mathrm{Hb}$ in phosphate buffer $\mathrm{pH}$ 7.4.

\subsection{Heated and Cooled}

$\mathrm{Hb}$, Hb-PAA-450k(1:0.8:1.5), Hb-PAA-450k(1:0.3:1.5), Hb-PAA-450k(1:0.8:1.5)-TEPA and Hb-PAA-450k(1:0.8:1.5)-PEI samples were heated at $80^{\circ} \mathrm{C}$ for $30 \mathrm{~min}$ in an oil bath followed by cooling for $1 \mathrm{~h}$ and $24 \mathrm{~h}$ at room temperature. Activity studies were performed using molecular devices; flex station 3, plate reader (Sunnyvale, CA, USA) at room temperature after cooling the samples.

\subsection{Steam Sterilization}

$\mathrm{Hb}, \quad H b-P A A-450 \mathrm{k}(1: 0.8: 1.5), \quad H b-P A A-450 \mathrm{k}(1: 0.3: 1.5), \quad$ Hb-PAA-450k(1:0.8:1.5)-PEI and Hb-PAA-450k(1:0.8:1.5)-TEPA were steam-sterilized using Amsco Century Scientific (Model SI-120, Steris, Mentor, OH, USA). All liquid samples were steam sterilized for $10 \mathrm{~min}$ at $122{ }^{\circ} \mathrm{C}(17-20 \mathrm{psi})$. Activity studies were performed after samples were cooled for $1 \mathrm{~h}$ and $24 \mathrm{~h}$ at room temperature, using molecular devices; flex station 3, plate reader (Sunnyvale, CA, USA).

\subsection{Calculating $K_{M}$ and $V_{\max }$ Values}

$K_{\mathrm{M}}$ and $V_{\max }$ values of $\mathrm{Hb}$ and $\mathrm{Hb}$-PAA conjugates were determined by performing peroxidase activity at different $o$-methoxyphenol concentrations $(0.5 \mathrm{mM}$ to $4 \mathrm{mM})$ using an HP 8453 diode array spectrophotometer (Agilent Technologies, Palo Alto, CA, USA). Lineweaver-Burk plots were constructed by plotting inverse initial rate $v s$. inverse $o$-methoxyphenol concentrations. Michaelis-Menton parameter $\left(K_{\mathrm{M}}\right)$ and the maximum velocity $\left(V_{\max }\right)$ were extracted from the plot. The concentration of the Hb part in all cases was kept at $1 \mu \mathrm{M}$ and the $\mathrm{H}_{2} \mathrm{O}_{2}$ concentration was $1 \mathrm{mM}$.

\subsection{Dynamic Light Scattering (DLS)}

Hydrodynamic radius of $\mathrm{Hb}$ and $\mathrm{Hb}-\mathrm{PAA}$ conjugates were measured using CoolBatch+dynamic light scattering apparatus, where a Precision detector (Varian Inc. Palo Alto, CA, USA) using a $0.5 \times 0.5 \mathrm{~cm}^{2}$ cuvette and $658 \mathrm{~nm}$ excitation laser source at $90^{\circ} \mathrm{C}$ geometry. Samples $(0.5 \mathrm{nM} \mathrm{Hb}$ or $0.5 \mathrm{nM} \mathrm{Hb}-\mathrm{PAA}$ in phosphate buffer $\mathrm{pH}$ 7.4) were filtered with 0.2-micron filter (PVDF, $13 \mathrm{~mm}$, Fisher Scientific) prior to the measurements. All samples were equilibrated for $300 \mathrm{~s}$ at $26^{\circ} \mathrm{C}$ and 5 repetitions with 60 accumulations were done at the same temperature. Precision Elucidate Version 1.1.0.9 was used to run the experiment and Deconvolve Version 5.5 was used to process the data. 


\subsection{Elemental Analysis}

To confirm the covalent conjugation of PAA $\left(M_{\mathrm{w}} 450 \mathrm{k}\right)$ to $\mathrm{Hb}$, elemental analysis was carried out with conjugates samples and compared the results with unmodified $\mathrm{Hb}$. All samples after covalent conjugation were dialyzed in $25 \mathrm{k} M \mathrm{w}$ dialysis tubing against deionized water to remove any unreacted EDC. After that water from the sample was removed by freeze-drying using FreeZone 6 Liter Console Freeze Dry System from LABCONCO (Kansas City, MO, USA) (catalog no. 7753024). Freeze-drying was carried out for three days under $-25{ }^{\circ} \mathrm{C}$ temperature and $0.024 \mathrm{~T}$ pressure using the above instrument. After that samples were sent to Galbraith Laboratories Inc. for elemental analysis

\subsection{Electrochemistry}

Cyclic Voltammetry and amperometric experiments were carried out using a Model CHI 601C electrochemical workstation (CH Instruments, Austin, TX, USA). A conventional three-electrode system was used with glassy carbon (GC) as working electrode, $\mathrm{Ag} / \mathrm{AgCl}$ as reference electrode and platinum as counter electrode. Before electrochemical measurement, the GC electrodes were polished with alumina powder ( $1 \mu \mathrm{m}$ and $50 \mathrm{~nm}$ respectively). Then the electrode is rinsed carefully with deionized water followed by sonication. After drying, $10 \mu \mathrm{L}$ of $5 \mu \mathrm{M}$ Hb-PAA nanogel conjugates was drop casted onto the electrode surface and dried in vacuum for five $\mathrm{h}$. EC experiments were carried out in PBS (0.1 M, $\mathrm{pH}$ 7.4). Prior to experiment, all the solutions were purged with nitrogen for $30 \mathrm{~min}$ and the nitrogen environment is maintained through the experiment. The charge $\mathrm{Q}$ under the reduction peak is calculated by integrating the area under the peak using $\mathrm{CHI}$ software.

\section{Results and Discussion}

\subsection{Conjugate Synthesis}

The nanogel conjugates were synthesized by crosslinking $\mathrm{Hb}$ and PAA450k using EDC with 1:x mole ratios of $\mathrm{Hb}$ to PAA45k, and $\mathrm{y}: 1$ mole ratios of EDC to $\mathrm{COOH}$ groups in PAA. The conjugates are named as Hb-PAA-450k(1:x:y). We test the hypothesis that the thermal stability and resistance to steam sterilization conditions $\left(122{ }^{\circ} \mathrm{C}, 40 \mathrm{~min}, 17-20 \mathrm{psi}\right)$ will improve by conjugation with the polymer in nanogels by systematically increasing the amount of PAA covalently attached to the protein. Mole ratio of Hb:PAA was altered from 1:0.3 to 1:0.8 such that increased PAA mole ratio augmented the average number of polymer chains attached per protein molecule. This resulted in a thicker polymer matrix around the protein, which could allow for improved stability by inhibiting protein denaturation due to the reduced entropy effect. The polar, water-soluble, ionic polymer shell prevents protein aggregation and it could enhance the reversibility of protein denaturation.

Most mammalian hemoglobins have roughly 44 lysine residues [24] per molecule and most of these amines could be attached to the carboxyl groups of PAA chains using EDC chemistry. The mole ratio of EDC: $\mathrm{COOH}$ was increased from 0.13 to 1.5 , by more than an order of magnitude to evaluate the influence of the degree of crosslinking on the chemical, physical and biological properties of the Hb-PAA conjugate. Our hypothesis is that strengthening of the polymer shell around the protein would increase protein stability and also improve the extent of reversibility of denaturation. Using EDC 
chemistry lysine- $\mathrm{NH}_{2}$ groups of $\mathrm{Hb}$ are conjugated with carboxyl groups of PAA ( $\left.M \mathrm{w} 450 \mathrm{k}\right)$. Again, the carboxyl groups of PAA are activated using EDC and the polymer chains are further crosslinked using polyamines TEPA and PEI. Thus, the conjugate was rationally designed and engineered to have the best thermal stability while retaining its enzyme-like activities, as well as its secondary structure, as presented below.

Increase in PAA wt \% as well as the mole ratio of EDC:COOH led to rapid heterogeneous gelation (Supplementary Materials Table S1). The samples were labeled based on visible observation of the sample viscosity as $\mathrm{L}=$ liquid, $\mathrm{TL}=$ thickened liquid, $\mathrm{G}=$ homogeneous gel, $\mathrm{HG}=$ heterogeneous gel, as in case of Hb-PAA-450k(1:3:0.5) increased molar ratio of PAA resulted in the formation of thickened gel. From this library of Hb-PAA conjugates (Supplementary Materials Tables S1 and S2) two conjugates Hb-PAA-450k(1:0.8:1.5) and Hb-PAA-450k(1:0.3:1.5) of low viscosity were selected for further studies to evaluate their activity, structure and electrochemistry. Hb-PAA-450k(1:0.3:1.5) has nearly three-times excess EDC per $\mathrm{COOH}$ of PAA when compared to previously reported Hb-PAA conjugate [24]. Therefore, comparison of these three samples revealed the influence of increased conjugation and increased PAA content of the conjugates.

Effect of further rigidification of the local environment was evaluated by cross linking Hb-PAA-450k(1:0.8:1.5) with two different polyamines, TEPA and PEI using EDC chemistry (Supplementary Materials Table S5). The influence of polyamine crosslinking was evaluated in steam sterilization studies.

\subsection{Agarose Gel Electrophoresis}

Agarose gel electrophoresis confirmed the covalent attachment of Hb to PAA (Figure 1A). The gel was run in $40 \mathrm{mM}$ Tris acetate at $\mathrm{pH}$ 6.5. At this $\mathrm{pH}, \mathrm{Hb}$ is slightly positively charged and migrated toward the negative electrode, while Hb-PAA samples migrated toward the positive electrode due to the excess negative charge on PAA. Hb (lane 1) migrated towards the negative electrode and lanes 2 and 4, contained the physical mixtures of $\mathrm{Hb}$ and PAA with compositions same as those of Hb-PAA-450k(1:0.8:1.5) and Hb-PAA-450k(1:0.3:1.5). The physical mixtures indicated unbound $\mathrm{Hb}$ and mere presence of PAA did not alter $\mathrm{Hb}$ migration. In sharp contrast to these lanes, the conjugates Hb-PAA-450k(1:0.8:1.5) and Hb-PAA-450k(1:0.3:1.5) (lanes 3 and 5, respectively) indicated movement in the opposite direction and indicated essentially complete conjugation of $\mathrm{Hb}$ to PAA, and there has been no detectable amounts of unbound $\mathrm{Hb}$ in these lanes.

\subsection{Elemental Analysis}

Conjugates showed decrease in nitrogen content and increase of carbon content when compared to the corresponding values of $\mathrm{Hb}$. The $\mathrm{C}: \mathrm{N}$ ratio for $\mathrm{Hb}$ is 3.35 while those of Hb-PAA-450k(1:0.3:1.5), Hb-PAA-450k(1:0.8:1.5), Hb-PAA-450k(1:0.8:1.5)-TEPA and Hb-PAA-450k(1:0.8:1.5)-PEI were 5.76, 8.26, 7.98 and 5.64, respectively. The increased $\mathrm{C}: \mathrm{N}$ ratio proves that the carbon-rich PAA has been conjugated to $\mathrm{Hb}$. Hb-PAA-450k(1:0.8:1.5) showed higher $\mathrm{C}: \mathrm{N}$ ratio than Hb-PAA-450k(1:0.3:1.5), since mole ratio of $\mathrm{Hb}: \mathrm{PAA}$ used with $\mathrm{Hb}-\mathrm{PAA}-450 \mathrm{k}(1: 0.8: 1.5)$ was 1:0.8 while that of Hb-PAA-450k (1:0.3:1.5) has been only 1:0.3. In case of cross-linked samples, Hb-PAA-450k(1:0.8:1.5)-PEI showed lesser $\mathrm{C}: \mathrm{N}$ ratio when compared to Hb-PAA-450k(1:0.8:1.5)-TEPA, since PEI is a polyimine with higher 
nitrogen content when compared to TEPA. These data strongly support conjugate synthesis and further crosslinking.
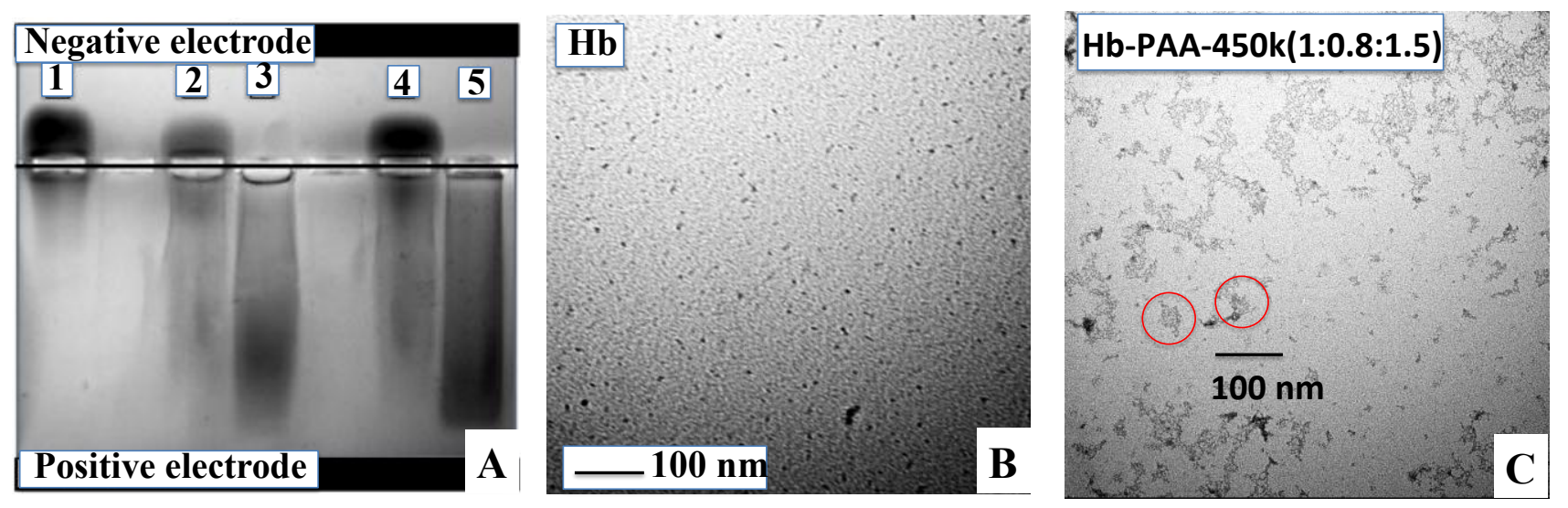

Figure 1. Covalent conjugation of $\mathrm{Hb}$ with PAA shown by agarose gel and TEM's. (A) Agarose gel of $\mathrm{Hb}$ and $\mathrm{Hb}-\mathrm{PAA}$ conjugates (40 mM Tris acetate $\mathrm{pH}$ 6.5). Lane 1, $\mathrm{Hb}$; lane 2, Hb/PAA-450k(1:0.8:1.5) physical mixture; lane 3, Hb-PAA-450k(1:0.8:1.5); lane 4, Hb/PAA-450k(1:0.3:1.5) physical mixture, and lane 5, Hb-PAA-450k(1:0.3:1.5). Hb migrated towards negative electrode (lane 1) and Hb-PAA migrated (lanes 3 and 5) towards the positive electrode due to the negatively charged carboxyl groups of PAA conjugated to $\mathrm{Hb}$; (B) TEM image of $\mathrm{Hb}$ (C) TEM image of Hb-PAA-450k(1:0.8:1.5) showing nanogels (also shown in circle). All TEM's are after staining with uranyl acetate.

\subsection{TEM and DLS}

Morphology of Hb-PAA conjugates were determined using TEM (Experimental in Supplementary Information). Figure $1 \mathrm{~B}$ shows the TEM image of the $\mathrm{Hb}$ in which discrete particles were noted. The TEM of Hb-PAA-450k(1:0.8:1.5) and Hb-PAA-450k(1:0.3:1.5) (Figure 1C, Supplementary Materials Figure S2C) samples clearly show nanogel structures that resulted from cross linking between $\mathrm{Hb}$ and PAA. TEM images are consistent with nanogel structure formation with $450 \mathrm{k}$ molecular weight PAA as reported earlier [24]. Extensive network structure was observed with Hb-PAA-450k(1:0.8:1.5)-TEPA and Hb-PAA-450k(1:0.8:1.5)-PEI conjugate samples which arise from excess cross-linking between PAA matrixes (Supplementary Materials Figure S2A,B). As previously reported, lower molecular weight PAA (8k) resulted in nanoparticles [25] but in the current case higher molecular weight PAA (450k) resulted in nanogels. As expected, higher PAA mole ratio (Hb-PAA-450k(1:0.8:1.5)) gave nanogels of larger size compared to that of lower mole ratio (Hb-PAA-450k(1:0.3:1.5)). Similarly, the overall size of the Hb-PAA nanogel decreased upon cross-linking.

Dynamic light scattering (DLS) data (Supplementary Materials Table S3) showed particle sizes of $85 \mathrm{~nm}$ for Hb-PAA-450k(1:0.8:1.5) and $63 \mathrm{~nm}$ for Hb-PAA-450k(1:0.3:1.5) conjugates. Particle size decreased when cross linked with polyamines, $70 \mathrm{~nm}$ for Hb-PAA-450k(1:0.8:1.5)-TEPA and $60 \mathrm{~nm}$ for Hb-PAA-450k(1:0.8:1.5)-PEI. The size and formation of soluble nanogels from DLS corroborated well with the TEM and agarose gel electrophoresis data. 


\subsection{Protein Structure Determination}

The Soret absorbance bands of Hb-PAA(1:0.8:1.5) and Hb-PAA(1:0.3:1.5) matched well with that of $\mathrm{Hb}$ (Figure 2A). The small shifts in the peak positions are negligible, and similar shift of the Soret band was observed upon PEGylation or methylation of $\mathrm{Hb}$ [26]. If heme were to be removed from its binding pocket during our conjugation reaction, the Soret peak would have shifted blue to almost $\sim 385 \mathrm{~nm}$, which did not happen with our Hb-PAA samples.
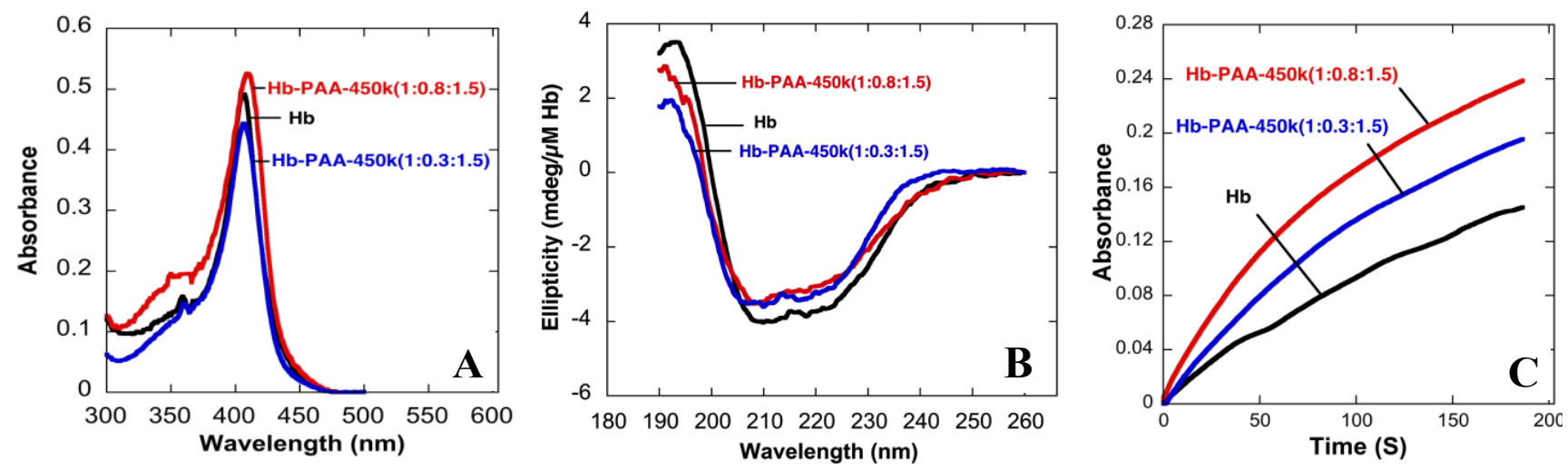

Figure 2. (A) Absorbance spectra of $\mathrm{Hb}$, Hb-PAA-450k(1:0.8:1.5) and Hb-PAA-450k (1:0.3:1.5); (B) Far UV CD spectra of Hb, Hb-PAA-450k(1:0.8:1.5) and Hb-PAA-450k (1:0.3:1.5); (C) Kinetic traces of $\mathrm{Hb}, \mathrm{Hb}, \mathrm{Hb}-\mathrm{PAA}-450 \mathrm{k}(1: 0.8: 1.5)$ and Hb-PAA-450k (1:0.3:1.5). All data collected in $10 \mathrm{mM}$ phosphate buffer $\mathrm{pH}$ 7.4.

The protein secondary structure was assessed by circular dichroism (CD) spectra (Figure $2 \mathrm{~B}$ ) and the CD spectra of Hb-PAA-450k(1:0.8:1.5), Hb-PAA-450k(1:0.8:1.5)-TEPA and Hb-PAA-450k(1:0.8:1.5)-PEI were compared with that of $\mathrm{Hb}$. All spectra were corrected for $\mathrm{Hb}$ concentration, path length and baseline (Supplementary Materials Figure S3). Peak positions and intensities of conjugates in the 190-250 nm, which is characteristic of the protein secondary structure, were consistent with the peak positions of unmodified $\mathrm{Hb}$, and thus indicating significant retention of protein secondary structure for the conjugates. The far UV CD spectrum of $\mathrm{Hb}$ (black line) has a peak maximum at $195 \mathrm{~nm}$ and two minima at 210 and $220 \mathrm{~nm}$. The same positions were observed for the conjugates; Hb-PAA-450k (1:0.8:1.5) (blue line), Hb-PAA-450k(1:0.8:1.5)-PEI and Hb-PAA-450k(1:0.8:1.5)-TEPA (Supplementary Materials Figure S3) with 70\%-90\% retention of the peak intensities.

\subsection{Peroxidase-Like Activity}

Prior to doing the electrochemical work, the conjugates were further characterized to ensure the retention of the redox activities of the heme center present in $\mathrm{Hb}$ in the conjugates. Even though $\mathrm{Hb}$ does not function as an enzyme in biological systems, its peroxidase-like activity is well known and it has been used to assess the biochemical competence of hemoglobin [27].

Peroxidase-like activities of $\mathrm{Hb}$ and its conjugates were monitored by following the oxidation of guaiacol (substrate) by hydrogen peroxide (oxidant). The resulting product absorbs at $470 \mathrm{~nm}$ and kinetics were determined from the initial slopes (Figure 2C and Supplementary Materials Figure S1). Specific activities of $\mathrm{Hb}$ and $\mathrm{Hb}-\mathrm{PAA}$ conjugates (Hb-PAA-450k(1:0.8:1.5), Hb-PAA-450k(1:0.3:1.5)), 
(Hb-PAA-450k(1:0.8:1.5)-PEI and Hb-PAA-450k(1:0.8:1.5)-TEPA) were estimated from the kinetic data (Figure 3A and Supplementary Materials Figure S4). The activities of the conjugates are shown relative to $\mathrm{Hb}$ as $100 \%$.
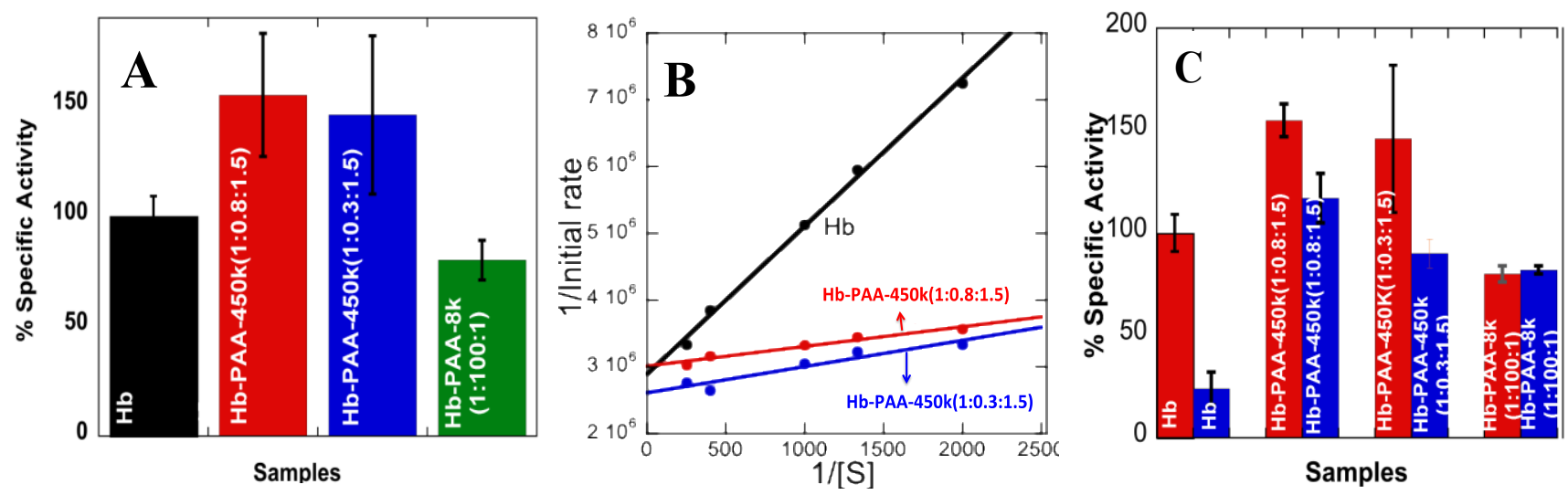

Figure 3. (A) Specific activities (compared to $\mathrm{Hb}, 100 \%$ ) of Hb-PAA-450k(1:0.8:1.5), Hb-PAA-450k(1:0.3:1.5), and Hb-PAA-8k(1:100:1) at room temperature; (B) Lineweaver-Burk plots for peroxidase activities of Hb, Hb-PAA-450k(1:0.8:1.5) and Hb-PAA-450k(1:0.3:1.5) samples; (C) Comparison of specific activities of $\mathrm{Hb}$ (compared to $\mathrm{Hb}, 100 \%$ ), $\mathrm{Hb}-\mathrm{PAA}-450 \mathrm{k}$ (1:0.8:1.5), Hb-PAA-450k(1:0.3:1.5), and Hb-PAA-8k(1:100:1) before (red) and after (blue) steam sterilization (cooled for $24 \mathrm{~h}$ ). Each bar is an average of three trials. All reactions were carried out in the presence of $1 \mu \mathrm{M}$ protein and $1 \mathrm{mM} \mathrm{H}_{2} \mathrm{O}_{2}$ in phosphate buffer $\mathrm{pH}$ 7.4, at room temperature.

Hb-PAA-450k(1:0.8:1.5) and Hb-PAA-450k(1:0.3:1.5) indicated improved activities (150\%) when compared to that of $\mathrm{Hb}$ and these are better than that of Hb-PAA-8k (4th bar). The gains were less when the conjugates were cross-linked with polyamines (Supplementary Materials Figure S4). Analysis of the initial rates with increasing substrate concentrations but under similar conditions of buffer, ionic strength and $\mathrm{pH}$ by Michaelis-Menton plots and Lineweaver-Burk plots (Figure 3B) to obtain the Michaelis-Menton constant $\left(K_{\mathrm{M}}\right)$ and the maximum velocity $\left(V_{\max }\right)$ (Table 1) [28], Figure 3B.

Table 1. $\mathrm{K}_{\mathrm{M}}, V_{\max }, k_{\text {cat }}$ and $k_{\mathrm{cat}} / K_{\mathrm{M}}$ values for $\mathrm{Hb}, \mathrm{Hb}-\mathrm{PAA}-450 \mathrm{k}(1: 0.8: 1.5)$ and Hb-PAA-450k (1:0.3:1.5) samples. $V_{\max }$ values of Hb-PAA conjugates are comparable to $\mathrm{Hb}$ and $K_{\mathrm{m}}$ values decreased considerably for $\mathrm{Hb}-\mathrm{PAA}$ conjugates in comparison to $\mathrm{Hb}$.

\begin{tabular}{ccccc}
\hline & $\boldsymbol{K}_{\mathbf{M}}$ & $\boldsymbol{V}_{\max }$ & $\boldsymbol{k}_{\text {cat }}$ & $\boldsymbol{k}_{\text {cat }} / \boldsymbol{K}_{\mathbf{M}}$ \\
\hline $\mathrm{Hb}$ & $0.76 \mathrm{mM}$ & $0.345 \cdot \mu \mathrm{M} \cdot \mathrm{s}^{-1}$ & $0.345 \cdot \mathrm{s}^{-1}$ & $4.54 \times 10^{2} \mathrm{M}^{-1} \cdot \mathrm{s}^{-1}$ \\
Hb-PAA-450k $(1: 0.8: 1.5)$ & $0.10 \mathrm{mM}$ & $0.332 \cdot \mu \mathrm{M} \cdot \mathrm{s}^{-1}$ & $0.332 \cdot \mathrm{s}^{-1}$ & $3.32 \times 10^{3} \mathrm{M}^{-1} \cdot \mathrm{s}^{-1}$ \\
Hb-PAA-450k(1:0.3:1.5) & $0.15 \mathrm{mM}$ & $0.383 \cdot \mu \mathrm{M} \cdot \mathrm{s}^{-1}$ & $0.383 \cdot \mathrm{s}^{-1}$ & $2.55 \times 10^{3} \mathrm{M}^{-1} \cdot \mathrm{s}^{-1}$ \\
\hline
\end{tabular}

The $V \max$ values of Hb-PAA-450k(1:0.8:1.5) and Hb-PAA-450k(1:0.3:1.5) are comparable to $\mathrm{Hb}$, but the $K_{\mathrm{M}}$ values decreased seven fold (Hb-PAA-450k(1:0.8:1.5)) when compared to that of $\mathrm{Hb}$. Decreased $K_{M}$ indicates increased substrate affinity to the Hb active site. Hb-PAA-450k(1:0.8:1.5) has smaller $K_{\mathrm{M}}$ than Hb-PAA-450k(1:0.3:0.5). This would directly increase the overall rate of the catalytic reaction, which is appreciated for practical applications. 


\subsection{Reversibility of Thermal Denaturation}

Prior to steam sterilization of the samples, we initially tested the thermal stability of the conjugates by heating the samples beyond the denaturation temperature $\left(80^{\circ} \mathrm{C}\right)$. If the denaturation is reversible, then the heat treated samples would have considerable retention of the Soret band and the catalytic activity. Absorbance spectra of $\mathrm{Hb}$, Hb-PAA-450k(1:0.8:1.5) and Hb-PAA-450k(1:0.3:1.5) samples before heating, at $80{ }^{\circ} \mathrm{C}$ and after cooling down to room temperature (Supplementary Materials Figure S5) showed that both Hb-PAA-450k(1:0.8:1.5) and Hb-PAA-450k(1:0.3:1.5) retained $~ 90 \%$ of the Soret band absorbance while $\mathrm{Hb}$ lost almost $50 \%$ of the Soret band intensity (Supplementary Materials Figure $\mathrm{S} 5 \mathrm{~B}, \mathrm{C})$. The conjugates underwent reversible thermal denaturation and these conclusions are tested by CD spectra.

The Soret CD spectra of Hb-PAA-450k(1:0.8:1.5), Hb-PAA-450k(1:0.3:1.5) and Hb before and after heating to $80{ }^{\circ} \mathrm{C}$ (Supplementary Materials Figure S6). Hb-PAA-450k(1:0.8:1.5) and Hb-PAA-450k (1:0.3:1.5) conjugates retained $\sim 50 \%$ of their initial Soret CD while Hb lost almost $70 \%$ of the band intensity. Hence, it is evident that at least $\sim 50 \%$ of the sample has refolded after thermal denaturation and cooling to room temperature and the extent of recovery depended on cooling time.

The influence of heating and cooling on the peroxidase activities were determined to guage the extent of recovery of activity, not just the secondary structure observed in the CD studies. Hb-PAA-450k (1:0.8:1.5), Hb-PAA-450k(1:0.8:1.5)-TEPA and Hb-PAA-450k(1:0.8:1.5)-PEI heated to $80{ }^{\circ} \mathrm{C}$ and cooled only $1 \mathrm{~h}$ retained $75 \%-85 \%$ of the initial activities (Supplementary Materials Figure S7) while $\mathrm{Hb}$ retained only $\sim 15 \%$ of its initial activity. Similarly, Hb-PAA-450k(1:0.3:1.5) retained 50\% of its initial activity upon heat treatment followed by cooling for one hour. The activities of Hb-PAA-450k (1:0.8:1.5), Hb-PAA-450k(1:0.3:1.5), Hb-PAA-450k(1:0.8:1.5)-PEI and Hb-PAA-450k(1:0.8:1.5)-TEPA improved after cooling for $24 \mathrm{~h}$ to $70 \%, 65 \%, 95 \%$ and $90 \%$, respectively. The crosslinking with the polyamines improved the extent of activity retention, in support of our hypothesis. These data prompted us to test the thermal stabilities of the conjugates on exposure to steam sterilization conditions as a bench mark for thermal stability.

\subsection{Stability towards Steam Sterilization}

Peroxidase-like activities of conjugates were monitored after the samples were steam sterilized (10 min at $122{ }^{\circ} \mathrm{C}$ and $17-20 \mathrm{psi}$, and cooling for $30 \mathrm{~min}$ ) and cooled back to room temperature for $24 \mathrm{~h}$ (Figure 3C). The samples, Hb-PAA-450k(1:0.8:1.5), Hb-PAA-450k(1:0.8:1.5)-PEI and Hb-PAA-450k (1:0.8:1.5)-TEPA retained almost $80 \%-90 \%$ of their initial activities, while $\mathrm{Hb}$ retained only $20 \%$ of its initial activity. Thus, (1) re-folding of denatured $\mathrm{Hb}$ depends on the extent of crosslinking, cooling time and (2) it is a kinetic phenomenon. Thus, in addition to the use of PAA to prepare and stabilize conjugates, polyamine cross-linking enhanced protein re-folding.

\subsection{Direct Electrochemistry of Hb-PAA Nanogels}

Encouraged by the above improvements in the thermal stabilities of the conjugates and due to their nanogel morphology, we hypothesized that these could serve as good model systems to evaluate their function in bioelectrodes. Direct electron transfer of $\mathrm{Hb}$-derivatives was already demonstrated by other 
researchers but the stability and activity of these systems have not been systematically investigated. We used Cyclic Voltammetry to study the direct electron transfer of Hb-PAA modified electrodes.

Cyclic voltammograms (CVs) of the Hb-electrodes in $0.1 \mathrm{M}$ phosphate buffered ( $\mathrm{PB}, \mathrm{pH} 7.4)$ are shown in Figure 4A. The CV of the Hb- electrode (Scheme 1, right top panel and black curve in Figure 4A showed very poor redox peaks while the electrode modified with Hb-PAA showed a pair of well-defined quasi-reversible redox peaks (red, green and blue). Thus, PAA not only favorably impacts the catalytic efficiency of $\mathrm{Hb}$, but also provide the suitable microenvironment for electron transfer between $\mathrm{Hb}$ and the underlying electrode. An increase in catalytic activity and electron transfer rate was seen when Myoglobin $(\mathrm{Mb})$ is covalently linked with PAA functionalized iron nanoparticles [29,30]. Among different Hb-PAA conjugates, Hb-PAA-450k(1:0.8:1.5) displayed more enhanced and sensitive redox peaks than the others. Based on the excellent peroxidase like activity (Figure 3A) and thermal stabilities (Figure 3C), Hb-PAA-450k(1:0.8:1.5) conjugate is chosen to be the best for further electrochemical studies.
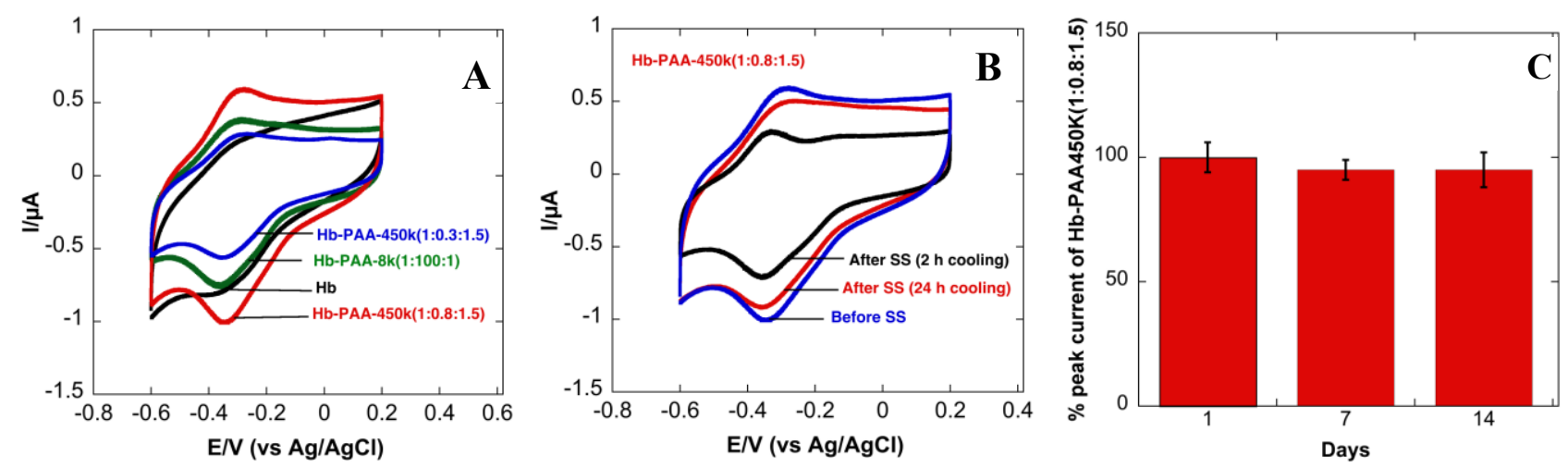

Figure 4. Improved stability: Cyclic voltammograms of Hb-PAA electrodes, (A) in $\mathrm{pH} 7.4$ PBS (0.1 M) before heat treatment; (B) Hb-PAA-450k(1:0.8:1.5) electrode after steam sterilization (SS) with $2 \mathrm{~h}$ cooling (black) and $24 \mathrm{~h}$ cooling (red) in $\mathrm{pH} 7.4 \mathrm{PBS}(0.1 \mathrm{M})$; (C) Stability of Hb-PAA-450k(1:0.8:1.5) electrodes at room temperature over 14 days.

The enhanced response of Hb-PAA-450k(1:0.8:1.5) clearly indicated that the direct electron transfer is greatly promoted by increased polymer concentration and increased covalent conjugation. The polymer dependent electron transfer is further verified by comparing the CVs of Hb-PAA-8k Hb-PAA-450k. Due to the highly water-soluble nature of Hb-PAA nanogels, the CVs were collected and compared in presence and absence of nafion after $30 \mathrm{~min}$ in $0.1 \mathrm{M}$ PBS with continuous nitrogen bubbling. In both cases, it displayed the same redox peak intensity (Supplementary Materials Figure S8), which indicates Hb-PAA nanogels are well adsorbed on the electrode surface.

The anodic and cathodic peak of $\mathrm{Hb}$ in Hb-PAA (Hb-PAA-450k(1:0.8:1.5)) are located at $0.279 \mathrm{~V}$ and $0.334 \mathrm{~V}$ with peak to peak separation of $55 \mathrm{mV}$ at the scan rate of $100 \mathrm{mV} / \mathrm{s}$. This peak to peak separation is smaller than $70 \mathrm{mV}$ for Nafion/Hb-MWCNT system in ionic liquid modified carbon paste electrode [31], $56 \mathrm{mV}$ for $\mathrm{Hb}$ microbelts [32], $70 \mathrm{mV}$ for $\mathrm{Hb}$ immobilized in sodium alginate-MWCNT composite film [33] but is higher than $\mathrm{Hb}$ at mesoporous carbon modified $\mathrm{GC}$ electrode (53 $\mathrm{mV})$ [34] at the same scan rate. This indicates quasi-reversible electron transfer of $\mathrm{Hb}$ in the Hb-PAA conjugate and is consistent with the characteristics redox of the heme proteins ( $\mathrm{Fe}(\mathrm{III}) / \mathrm{Fe}(\mathrm{II})$ ) [35]. The concentration $\left(\mathrm{mol} / \mathrm{cm}^{2}\right)$ of electroactive $\mathrm{Hb}$ on the electrode surface was determined by integrating the reduction peak 
according the equation, $\Gamma=Q / n F A$, where $\Gamma$ is the concentration of electroactive $\mathrm{Hb}, Q$ is charge involved in reaction calculated by integrating the reduction peak using software $\left(5.665 \times 10^{-7} \mathrm{C}\right), n$ is number of electrons transferred, $\mathrm{A}$ is area of the electrode $\left(7.06 \times 10^{-2} \mathrm{~cm}^{2}\right)$ and $\mathrm{F}$ is Faraday constant $(96,485 \mathrm{C} / \mathrm{mol})$. Out of $7.08 \times 10^{-7} \mathrm{~mol} / \mathrm{cm}^{2}$ deposited on electrode surface, the concentration of electroactive $\mathrm{Hb}$ was estimated to be $8.31 \times 10^{-11} \mathrm{~mol} / \mathrm{cm}^{2}(0.01 \%)$, assuming one electron transfer. This is 4.4 times higher than the theoretical monolayer coverage of $\mathrm{Hb}, 1.89 \times 10^{-11} \mathrm{~mol} / \mathrm{cm}^{2}$ [36], which is higher than 1.6 times for $\mathrm{Hb}$ entrapped in agarose hydrogel in RT ionic liquid [36], 4.0 times for $\mathrm{Hb}$ immobilized in polyacrylamide-P123 [37] but smaller than most of the system with $\mathrm{Hb}$ immobilized in CNTs. CNTs are known to bridge between the layers, thus, making the electron hopping possible to larger distance from electrode surface thus resulting 114 times more electroactive species for $\mathrm{Hb}$ immobilized in graphene/CNTs [31], 21 times more electroactive species for Hb immobilized in sodium alginate-MWCNT composite film [33]. Our data, in comparison to published literature, suggests multi layers of Hb-PAA are present on the electrode and enough concentration of electroactive $\mathrm{Hb}$ species is present in these layers which allows this material to be electroactive even in the absence of conducting carbon inclusions.

\subsection{Stability of Hb-PAA-450k(1:0.8:1.5) Modified GC Electrodes}

\subsubsection{Cyclic Voltammetry of Steam Sterilized Samples}

The cyclic voltammetry of Hb-PAA-450k(1:0.8:1.5) was recorded before and after steam-sterilization (SS). Figure $4 \mathrm{~B}$ shows $\sim 65 \%$ retention in peak current within $2 \mathrm{~h}$ (black) and $\sim 90 \%$ after $24 \mathrm{~h}$ (red) of cooling at room temperature. This observation further supports the idea that $\mathrm{Hb}$ re-folding in $\mathrm{Hb}$-PAA conjugate is a kinetic phenomenon and substantial re-folding occurs within $24 \mathrm{~h}$. The peak intensity of $\mathrm{Hb}$ intercalated in zirconium phosphate decreased beyond $85^{\circ} \mathrm{C}$ indicating the denaturation of the protein [38].

\subsubsection{Stability with Time at Room Temperature}

The extended stability of Hb-PAA modified electrode at room temperature was tested by monitoring the electroactivities of three Hb-PAA (Hb-PAA-450k(1:0.8:1.5)) electrodes maintained at ambient conditions. The peak current decreased by only 5\% after two weeks, indicating the high stability of the electrodes (Figure 4C) over this time period at room temperature. Most enzymes are usually unstable and the enzyme-electrodes are generally stored at $4{ }^{\circ} \mathrm{C}$. Increased stability of the Hb-PAA electrodes (95\% retention in peak current) is comparable to $96 \%$ retention reported using $\mathrm{Hb}$ loaded onto $\mathrm{ZnO}$ nanoparticle/ionic liquid system [39], 95\% retention in graphene/ $\mathrm{Fe}_{3} \mathrm{O}_{4}$ nanocomposites [40] at $4{ }^{\circ} \mathrm{C}$, over the same time period. The increased stability observed with Hb-PAA offer opportunities to build better biosensors with enhanced room temperature storage or wide temperature range applications in contrast to denaturation and subsequent loss in the electroactivity of unprotected enzymes.

\subsection{Hb-PAA-450k(1:0.8:1.5) Modified GC Electrode for $\mathrm{H}_{2} \mathrm{O}_{2}$ Detection}

The peroxidase-like activities of Hb-PAA conjugates synthesized using 450k PAA in solutions was better than $\mathrm{Hb}$ itself. Now, the electrocatalytic activity of the same was investigated using cyclic voltammetry $(\mathrm{CV})$. 
Figure 5A shows the CVs of Hb-PAA (Hb-PAA-450k(1:0.8:1.5) in absence and presence of different concentration of $\mathrm{H}_{2} \mathrm{O}_{2}$. The peak current increases linearly with $\mathrm{H}_{2} \mathrm{O}_{2}$ concentration and saturates at about $370 \mu \mathrm{M}$. The corresponding calibration plot is shown in inset of Figure 5A. Amperometry is more than $\mathrm{CV}$ and was used to determine the response of the Hb-PAA modified electrode with different concentration of $\mathrm{H}_{2} \mathrm{O}_{2}$ (Figure 5B) The amperomety showed linear response up to $120 \mu \mathrm{M} \mathrm{H}_{2} \mathrm{O}_{2}$ (Figure 5C) at an applied potential of $-0.335 \mathrm{v}$ with a detection limit of $0.5 \mu \mathrm{M}$. This detection limit is compared with the recently reported $\mathrm{Hb}$ based $\mathrm{H}_{2} \mathrm{O}_{2}$ biosensors, Table 2, and proved that the detection limit of our system is comparable to other Hb/polymer systems albeit with enhanced storage stability and ability to reversibly denature.

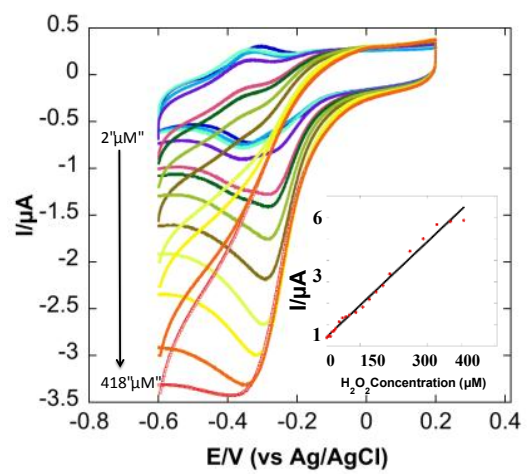

(A)

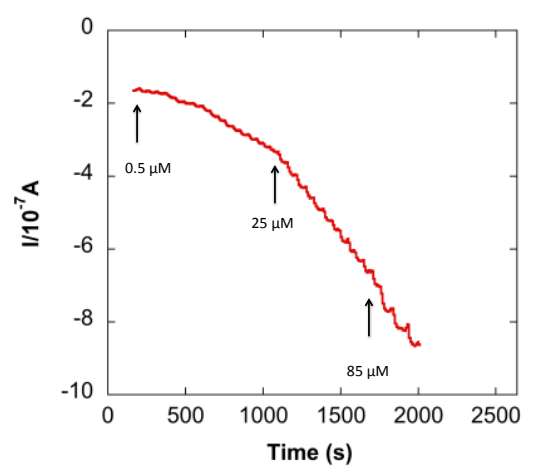

(B)

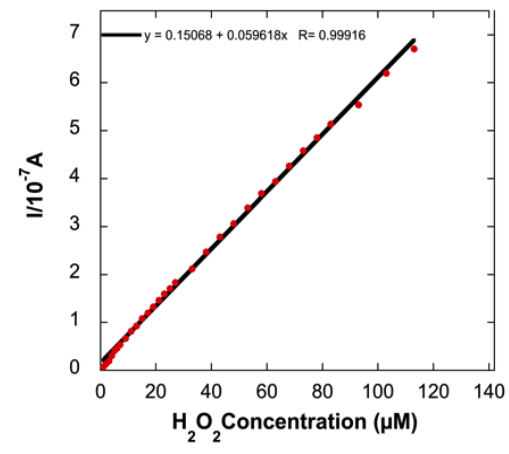

(C)

Figure 5. (A) Cyclic Volatmmograms of Hb-PAA-450k(1:0.8:1.5) modified GC electrode at different concentration of $\mathrm{H}_{2} \mathrm{O}_{2}$ (Inset: corresponding calibration plot); (B) Amperometric response of $\mathrm{Hb}$-PAA modified electrode with successive additions of $\mathrm{H}_{2} \mathrm{O}_{2}$ in $\mathrm{PB}$ pH 7.4 at an applied potential of $-0.335 \mathrm{~V}$ at $25{ }^{\circ} \mathrm{C}$; (C) Corresponding calibration plot of amperometric response towards $\mathrm{H}_{2} \mathrm{O}_{2}$.

Table 2. Relevant data from recently reported $\mathrm{Hb}$-based $\mathrm{H}_{2} \mathrm{O}_{2}$ biosensors.

\begin{tabular}{|c|c|c|c|c|}
\hline Electrode & Applied Potential & Electrolyte, pH & $\begin{array}{c}\text { Detection } \\
\text { Limit }(\boldsymbol{\mu M})\end{array}$ & Reference \\
\hline $\mathrm{Hb} / \mathrm{PAN}-\mathrm{co}-\mathrm{PAA}$ & - & 0.1 M phosphate, $\mathrm{pH} 7.0$ & 4.5 & [41] \\
\hline $\mathrm{Hb} /$ sodium alginate-MWCNTs & $-0.4 \mathrm{~V}(v s . \mathrm{SCE})$ & 0.1 M phosphate, $\mathrm{pH} 7.0$ & 16.41 & [33] \\
\hline $\mathrm{Hb}$ microbelts & $-0.377 \mathrm{~V}(v s . \mathrm{Ag} / \mathrm{AgCl})$ & 0.1 M phosphate, $\mathrm{pH} 7.0$ & 0.61 & {$[32]$} \\
\hline $\mathrm{Hb} / \mathrm{MoS}_{2}$ & - & 0.1 M phosphate, $\mathrm{pH} 7.0$ & 6.7 & [42] \\
\hline Polystyrene-Block-PAA/Hb & $-0.25 \mathrm{~V}(v s . \mathrm{SCE})$ & $0.1 \mathrm{M}$ phosphate, $\mathrm{pH} 6.5$ & 12 & [43] \\
\hline Hb-PAA-450k & $-0.335 \mathrm{~V}(v s . \mathrm{Ag} / \mathrm{AgCl})$ & $0.1 \mathrm{M}$ phosphate, $\mathrm{pH} 7.4$ & 0.5 & This study \\
\hline
\end{tabular}

\section{Conclusions}

We systematically investigated the influence of polymer molecular weight, $\mathrm{Hb}$ to polymer mole ratio and the amount of crosslinking on the thermal and electrochemical properties of Hb-PAA nanogels. Nanogels produced with high molecular weight PAA $\left(M_{\mathrm{W}} 450 \mathrm{k}\right)$ at high Hb:PAA ratio, at high EDC: $\mathrm{COOH}$ mole ratios indicated reversible thermal denaturation of conjugated $\mathrm{Hb}$. Interestingly, this $\mathrm{Hb}$-PAA nanogel in the absence of a mediator presented excellent electrochemical response towards $\mathrm{H}_{2} \mathrm{O}_{2}$ with the detection limit of $0.5 \mu \mathrm{M}$. Thus, chemical modification of $\mathrm{Hb}$ with PAA enhanced direct 
communication of the $\mathrm{Hb}$ redox center with the underlying electrode. These $\mathrm{Hb}$-PAA modified electrodes are stable at room temperature for two weeks with $95 \%$ retention in their electrochemical properties, which removes the need for refrigeration of the bioelectrodes. The approach for bioelectrode stabilization is modular, and current approach can be extended to other proteins or enzymes that have appropriate ligation sites on their surfaces.

There are several features of the Hb-PAA nanogels that are likely responsible for the observed retention in biocatalytic and electrocatalytic activity after exposure to denaturing conditions. First, a major factor is the presence of a substantial polymer shroud around the protein and in the nanogel network that effectively prevented the agglomeration and precipitation of the denatured protein. Further crosslinking by amines robust the polymeric shell around the protein and helps in refolding. This polymeric layer also prevented the denaturation of protein at the electrode surface; second, physical confinement of $\mathrm{Hb}$ molecules within nanogel networks shield the protein from the external microenvironment and thus enhanced its stability. By increasing the polymer molecular weight, polymer to $\mathrm{Hb}$ mole ratio, and with increased EDC: $\mathrm{COOH}$ mole ratio, the polymer shroud around $\mathrm{Hb}$ is strengthened, thickened or rigidified to enhanced its ability to protect $\mathrm{Hb}$ against denaturation and promoted refolding of the denatured protein. This aspect is similar to the effect of networks in shape memory polymers. Finally, crosslinking between the protein and hydrophilic PAA maintained a hydrophilic environment at the electrode surface and protected protein secondary structure and heme retention in the active site. Hydrophilic environment around the protein has been shown to increase electron transfer rates [44] and this could be an important parameter in the current studies.

When all of the above-discussed factors act in concert, and the synergistic result is the increased, resistance of the $\mathrm{Hb}$-electrode to thermal deactivation and promoted efficient electron transfer. Overall, higher resistance to deactivation by heat is a welcome change for applications in high temperature biocatalysis, sterilization and in the production of novel, sterile biomaterials and robust biocatalysts for sensing and fuel cell applications. Since the improvements in the bioelectrode properties are mostly due to the polymer matrix surrounding the protein, our modular approach is likely to be useful in stabilizing bioelectrodes of other enzymes as well, but this needs to be tested in future studies. This hypothesis will be valuable in directing research to enhance bioelectrode stabilities and their electroactivities.

\section{Acknowledgments}

Financial support for this work was provided by the Office of the Vice President for Research (OVPR) Research Excellence Program (REP) 2015 grant. C.V.K. also thanks the NSF EAGER award for financial support of this work (DMR-1441879).

\section{Conflicts of Interest}

The authors declare no conflict of interest.

\section{References}

1. Yu, E.H.; Scott, K. Enzymatic Biofuel Cells-Fabrication of Enzyme Electrodes. Energies 2010, $3,23-42$. 
2. Li, J.; Liu, L.; Yan, R.; Xiao, M.; Liu, L.; Zhao, F.; Zeng, B. Enhanced direct electron transfer reactivity of hemoglobin in cationic gemini surfactant-room temperature ionic liquid composite film on glassy carbon electrodes. Electrochim. Acta 2008, 53, 4591-4598.

3. $\mathrm{Xu}, \mathrm{Y} . ; \mathrm{Hu}, \mathrm{C} . ; \mathrm{Hu}, \mathrm{S}$. Single-chain surfactant monolayer on carbon paste electrode and its application for the studies on the direct electron transfer of hemoglobin. Bioelectrochem. Amst. Neth. 2009, 74, 254-259.

4. Zeng, X.; Wei, W.; Li, X.; Zeng, J.; Wu, L. Direct electrochemistry and electrocatalysis of hemoglobin entrapped in semi-interpenetrating polymer network hydrogel based on polyacrylamide and chitosan. Bioelectrochemistry 2007, 71, 135-141.

5. Zheng, W.; Zheng, Y.F.; Jin, K.W.; Wang, N. Direct electrochemistry and electrocatalysis of hemoglobin immobilized in $\mathrm{TiO}_{2}$ nanotube films. Talanta 2008, 74, 1414-1419.

6. Xu, H.; Dai, H.; Chen, G. Direct electrochemistry and electrocatalysis of hemoglobin protein entrapped in graphene and chitosan composite film. Talanta 2010, 81, 334-338.

7. Huang, C.; Bai, H.; Li, C.; Shi, G. A graphene oxide/hemoglobin composite hydrogel for enzymatic catalysis in organic solvents. Chem. Commun. 2011, 47, 4962-4964.

8. Kumar, C.V.; Chaudhari, A. Efficient Renaturation of Immobilized Met-Hemoglobin at the Galleries of $\alpha$-Zirconium Phosphonate. Chem. Mater. 2001, 13, 238-240.

9. Kumar, C.V.; Chaudhari, A. High temperature peroxidase activities of HRP and hemoglobin in the galleries of layered $\mathrm{Zr}$ (IV)phosphate. Chem. Commun. 2002, 20, 2382-2383.

10. Kumar, C.V.; Chaudhari, A. Proteins Immobilized at the Galleries of Layered $\alpha$-Zirconium Phosphate: Structure and Activity Studies. J. Am. Chem. Soc. 2000, 122, 830-837.

11. Wang, Q.; Gao, Q.; Shi, J. Enhanced Catalytic Activity of Hemoglobin in Organic Solvents by Layered Titanate Immobilization. J. Am. Chem. Soc. 2004, 126, 14346-14347.

12. Kim, J.; Grate, J.W.; Wang, P. Nanostructures for enzyme stabilization. Chem. Eng. Sci. 2006, 61, 1017-1026.

13. Kim, J.; Grate, J.W. Single-Enzyme Nanoparticles Armored by a Nanometer-Scale Organic/Inorganic Network. Nano Lett. 2003, 3, 1219-1222.

14. Novick, S.J.; Dordick, J.S. Preparation of Active and Stable Biocatalytic Hydrogels for Use in Selective Transformations. Chem. Mater. 1998, 10, 955-958.

15. Klibanov, A.M. Enzyme stabilization by immobilization. Anal. Biochem. 1979, 93, 1-25.

16. Martinek, K.; Klibanov, A.M.; Goldmacher, V.S.; Tchernysheva, A.V.; Mozhaev, V.V.; Berezin, I.V.; Glotov, B.O. The principles of enzyme stabilization: II. Increase in the thermostability of enzymes as a result of multipoint noncovalent interaction with a polymeric support. Biochim. Biophys. Acta BBA Enzymol. 1977, 485, 13-28.

17. Khmelnitsky, Y.L.; Belova, A.B.; Levashov, A.V.; Mozhaev, V.V. Relationship between surface hydrophilicity of a protein and its stability against denaturation by organic solvents. FEBS Lett. 1991, 284, 267-269.

18. Gill, I.; Pastor, E.; Ballesteros, A. Lipase-Silicone Biocomposites: Efficient and Versatile Immobilized Biocatalysts. J. Am. Chem. Soc. 1999, 121, 9487-9496.

19. Hill, T.G.; Wang, P.; Huston, M.E.; Wartchow, C.A.; Oehler, L.M.; Smith, M.B.; Bednarski, M.D.; Callstrom, M.R. Carbohydrate protein conjugates (CPC): The design of new materials to stabilize enzymes. Tetrahedron Lett. 1991, 32, 6823-6826. 
20. Yang, Z.; Mesiano, A.J.; Venkatasubramanian, S.; Gross, S.H.; Harris, J.M.; Russell, A.J. Activity and Stability of Enzymes Incorporated into Acrylic Polymers. J. Am. Chem. Soc. 1995, 117, 4843-4850.

21. Yang, Z.; Williams, D.; Russell, A.J. Synthesis of protein-containing polymers in organic solvents. Biotechnol. Bioeng. 1995, 45, 10-17.

22. Wang, P.; Hill, T.G.; Wartchow, C.A.; Huston, M.E.; Oehler, L.M.; Smith, M.B.; Bednarski, M.D.; Callstrom, M.R. New carbohydrate-based materials for the stabilization of proteins. J. Am. Chem. Soc. 1992, 114, 378-380.

23. Yan, M.; Ge, J.; Liu, Z.; Ouyang, P. Encapsulation of Single Enzyme in Nanogel with Enhanced Biocatalytic Activity and Stability. J. Am. Chem. Soc. 2006, 128, 11008-11009.

24. Thilakarathne, V.; Briand, V.A.; Zhou, Y.; Kasi, R.M.; Kumar, C.V. Protein Polymer Conjugates: Improving the Stability of Hemoglobin with Poly(acrylic acid). Langmuir 2011, 27, 7663-7671.

25. Mudhivarthi, V.K.; Cole, K.S.; Novak, M.J.; Kipphut, W.; Deshapriya, I.K.; Zhou, Y.; Kasi, R.M.; Kumar, C.V. Ultra-stable hemoglobin-poly(acrylic acid) conjugates. J. Mater. Chem. 2012, 22, 20423-20433.

26. Torres, E.; Vazquez-Duhalt, R. Chemical Modification of Hemoglobin Improves Biocatalytic Oxidation of PAHs. Biochem. Biophys. Res. Commun. 2000, 273, 820-823.

27. Glick, D.; Maehly, A.C. Assay of catalases and peroxidases. Methods Biochem. Anal. 1955, doi:10.1002/9780470110171.ch14.

28. Voet, D.; Voet, J.G. Biochemistry, 3rd ed.; John Wiley and Sons: New York, NY, USA, 1995; pp. $477-495$.

29. Krishnan, S.; Walgama, C. Electrocatalytic features of a heme protein attached to polymer-functionalized magnetic nanoparticles. Anal. Chem. 2013, 85, 11420-11426.

30. Prasad, K.S.; Walgama, C.; Krishnan, S. Enhanced electroactivity and substrate affinity of microperoxidase-11 attached to pyrene-linkers $\pi$ - $\pi$ stacked on carbon nanostructure electrodes. RSC Adv. 2015, 5, 11845-11849.

31. Sun, W.; Cao, L.; Deng, Y.; Gong, S.; Shi, F.; Li, G.; Sun, Z. Direct electrochemistry with enhanced electrocatalytic activity of hemoglobin in hybrid modified electrodes composed of graphene and multi-walled carbon nanotubes. Anal. Chim. Acta 2013, 781, 41-47.

32. Ding, Y.; Wang, Y.; Li, B.; Lei, Y. Electrospun hemoglobin microbelts based biosensor for sensitive detection of hydrogen peroxide and nitrite. Biosens. Bioelectron. 2010, 25, 2009-2015.

33. Zhao, H.Y.; Zheng, W.; Meng, Z.X.; Zhou, H.M.; Xu, X.X.; Li, Z.; Zheng, Y.F. Bioelectrochemistry of hemoglobin immobilized on a sodium alginate-multiwall carbon nanotubes composite film. Biosens. Bioelectron. 2009, 24, 2352-2357.

34. Pei, S.; Qu, S.; Zhang, Y. Direct Electrochemistry and Electrocatalysis of Hemoglobin at Mesoporous Carbon Modified Electrode. Sensors 2010, 10, 1279-1290.

35. Jian, F.; Qiao, Y.; Zhuang, R.; Direct electrochemistry of hemoglobin in TATP film: Application in biological sensor. Sens. Actuators B Chem. 2007, 124, 413-420.

36. Wang, S.-F.; Chen, T.; Zhang, Z.-L.; Shen, X.-C.; Lu, Z.-X.; Pang, D.-W.; Wong, K.-Y. Direct Electrochemistry and Electrocatalysis of Heme Proteins Entrapped in Agarose Hydrogel Films in Room-Temperature Ionic Liquids. Langmuir 2005, 21, 9260-9266. 
37. Li, J.; Tang, J.; Zhou, L.; Han, X.; Liu, H. Direct electrochemistry and electrocatalysis of hemoglobin immobilized on polyacrylamide-P123 film modified glassy carbon electrode. Bioelectrochemistry 2012, 86, 60-66.

38. Liu, Y.; Lu, C.; Hou, W.; Zhu, J.-J. Direct electron transfer of hemoglobin in layered $\alpha$-zirconium phosphate with a high thermal stability. Anal. Biochem. 2008, 375, 27-34.

39. Wang, D.-D.; Liu, H.-J.; Zhao, C.-Z.; Hui, N.; Sun, W. Electrocatalysis of Hemoglobin in ZnO Nanoparticle/Ionic Liquid Composite Film Modified Glassy Carbon Electrode. J. Chin. Chem. Soc. 2010, 57, 99-104.

40. Wang, Y.; Zhang, H.; Yao, D.; Pu, J.; Zhang, Y.; Gao, X.; Sun, Y. Direct electrochemistry of hemoglobin on graphene/ $\mathrm{Fe}_{3} \mathrm{O}_{4}$ nanocomposite-modified glass carbon electrode and its sensitive detection for hydrogen peroxide. J. Solid State Electrochem. 2012, 17, 881-887.

41. Shan, D.; Cheng, G.; Zhu, D.; Xue, H.; Cosnier, S.; Ding, S. Direct electrochemistry of hemoglobin in poly(acrylonitrile-co-acrylic acid) and its catalysis to $\mathrm{H}_{2} \mathrm{O}_{2}$. Sens. Actuators B Chem. 2009, 137, 259-265.

42. Liu, H.; Su, X.; Duan, C.; Dong, X.; Zhu, Z. A novel hydrogen peroxide biosensor based on immobilized hemoglobin in 3D flower-like $\mathrm{MoS}_{2}$ microspheres structure. Mater. Lett. 2014, 122, $182-185$.

43. Xu, J.; Zhu, Z.; Xue, H. Porous polystyrene-block-poly(acrylic acid)/hemoglobin membrane formed by dually driven self-assembly and electrochemical application. ACS Appl. Mater. Interfaces 2015, 7, 8852-8858.

44. Yeh, P.; Kuwana, T. Reversible electrode reaction of cytochrome c. Chem. Lett. 1977, 6, 1145-1148.

(C) 2015 by the authors; licensee MDPI, Basel, Switzerland. This article is an open access article distributed under the terms and conditions of the Creative Commons Attribution license (http://creativecommons.org/licenses/by/4.0/). 